\title{
THE 2003 INFORMATION MANAGEMENT AWARDS
}

Information is the lifeblood of the modern business world; in today's global marketplace, organisations that successfully manage their information and knowledge assets to improve performance and enhance the customer experience will enjoy a huge competitive advantage.

The Information Management Awards, now in their ninth year, are the premier European recognition of excellence and innovation in the management of business information. The presentations took place at the IM2003 Awards dinner at the Grosvenor House Hotel in London on 4 December, attended by nearly 1000 finalists, press and guests.

The Business Intelligence Project Award category is sponsored by SAS and the media partner is the Journal of Database Marketing \& Customer Strategy Management. This year 18 entries reached the final stage. The winner was high street electrical retailer Comet's Project Odyssey, in partnership with Conchango. The runner up was Deutsche Bank; cable company ntl received a commendation for third place. The full list of finalists is shown in the Table. The full list of finalists for other categories can be found at www.elanconf.co.uk/im2003.

This is a synopsis of Project Odyssey. It contains a brief description of the project, the business rationale, how it was implemented and the business benefits realised.

\section{SHARING KNOWLEDGE TO PROMOTE BEST PRACTICE AND INCREASE SALES}

Determined to maintain its competitive edge, Comet conducted a series of internal studies that revealed a marked difference in performance from store to store. Some were achieving profits around 30 per cent higher than others. Comet embarked on Project Odyssey to discover what managers of these successful stores were doing - and, importantly, to share this information across the company.
Having previously worked with Comet on a data warehousing project, and with a track record in business intelligence solutions, Conchango joined the Odyssey team to advise on and then implement a technology-led solution for classifying and sharing sales, consumer behaviour, market basket analysis, employee contributions to sales and effectiveness, and profit and margin data across the retail network. Comet selected Microstrategy's Web Professional software as the basis for its new business intelligence portal. To ensure rapid ROI 
and to meet stringent deadlines, Conchango leveraged Comet's existing Oracle-based data warehouse system and sourced information directly from the AS/400 operational systems. The new system was piloted to 25 per cent of the Comet estate and received such high praise that it was quickly expanded to an additional 25 per cent of the estate within two weeks and the entire UK Comet estate one week after. Within weeks, profitability and efficiency increases within the stores were being recognised, with some stores increasing their profits by up to 30 per cent.

\section{GREATER PRODUCTIVITY ON THE SHOP FLOOR}

Comet did not want the expense of a brand new system, requiring instead that the MicroStrategy solution worked within its existing technology framework. In tandem with Comet's IS team, Conchango adapted the MicroStrategy software, interfacing and enhancing the retailer's existing data warehouse system and leveraging its considerable existing investment. It was not possible to leverage all of the data from the data warehouse due to technology limitations, so Conchango devised a clever way of interfacing the MicroStrategy software directly with the AS/400 systems, allowing all information to be delivered with a similar look and feel via the portal.

A major leap forward in Comet's internal communication processes, this intranet-based solution is now delivering crucial business benefits, including:

- Improved management information giving the company's decision-makers greater scope for accurate, performance-led strategy development.

- Increased turnover per square metre store managers are now able to measure their performance against other stores in the same region, giving them an incentive to compete for a greater share of customer spend by selling more, higher value products.

- More effective allocation of floor space for those products proven to sell well and the minimisation of space for the slow-moving product lines, based on up-to-date information shared between stores.

- Centrally stored and easily accessible data on individual sales performance gives associates an incentive to encourage add-on purchases or upgrades to higher value products.

- A faster more focused response to consumer trends - loading data into the data warehouse so that it is ready for analysis the next morning.

- A single set of figures that both stores and Head Office utilise for measurements and communications in the past, these two areas used different systems and therefore reported differing results which could lead to potential confusion in discussions. This has now been eliminated.

\section{MAKING SALES DATA WORK HARD}

Conchango's relationship-based approach enabled it to adapt quickly to Comet's way of working when it joined the existing Project Odyssey team. A series of business analyses established the key behaviours at top performing stores and Conchango's task was to ensure that these key performance indicators (KPIs) were designed so that they could be easily understood by the stores. Conchango's business intelligence analysts needed to convert the abstract requirements into easy-to-understand reports which highlighted key information quickly. Conchango selected exception reporting to ensure that the store managers did not have to pore over volumes of reports and data to receive 
the results and to maximise their time on the shop floor, thus increasing profitability. They receive relevant, timely and accurate information on their performance only when exceptions occur, allowing them to highlight issues swiftly and focus on potential problems quickly and effectively.

Importantly, Comet needed these KPIs to be ready for the Christmas period so that managers could maximise sales at the busiest time of the year. This gave the project team just four months to analyse the information collected, design the solution and incorporate it into the updated system, which in turn had to be interfaced with Comet's back-office system. The Conchango/Comet team also had to undertake extensive testing (unit, system, user acceptance) as well as pilot the solution. During user acceptance testing, an iterative process was adopted that meant user-requested changes were typically engineered into the system and released within a 24-hour time frame. This process was also utilised during the pilot, resulting in a significant portion of store managers' comments and ideas being implemented in the system before general release. User perception and usability of the system were key aspects of the solution to ensure end user buy-in and overall effectiveness of the solution. It was recognised that in the highly competitive consumer electricals sector the solution had to be quickly adopted by the store managers if the solution's ROI and business targets were to be met.

To ensure that the project delivered exactly what Comet needed, regular meetings were held between Conchango and the Retail Communications Manager to discuss how the system could add value and, crucially, contribute to the business's bottom line. These sessions were scheduled on at least a fortnightly basis and were constructed to ensure that both Retail Operations and Conchango could maximise the effectiveness of the solution. This kept open lines of communication, enabling the project to come in early and under budget.

Leveraging Comet's existing central data warehouse technology to keep costs to a minimum, Conchango reorganised Comet's sales data into logical, easy-to-understand sequences thus increasing the overall efficiency of the solution without Comet having to re-invest in technology. This re-usability approach ensured that the business requirements could be met whilst keeping development timeframes and project costs to an absolute minimum. An added complication was that Comet was examining their base technology infrastructure, considerable expenditure on the data warehouse could, therefore, have resulted in ROI of other projects being affected in the solution, as well as Comet's overall Information Technology Architecture plans. The solution was designed so that, where possible, existing technology was leveraged; moreover the system was designed in such a way that porting it to a different underlying database technology in the future could be done with minimal redesign.

The system now generates a suite of exception-based reports that clearly show buying patterns within geographic regions. For example, store managers and head office staff can identify both the ten top-selling and the ten poorest-selling products store-by-store, as well as the most profitable lines and general sales figures. Geographical store grouping allows stores in similar catchment areas to compare their results. This ensures that the stores provide items for sale that the consumers in their areas want, reducing stagnant stock, and reducing overall mark-downs and inventory clearance sales, thereby increasing overall group 
IM2003 Awards - Winners and finalists: Business intelligence category

\begin{tabular}{llll}
\hline Project/product owner & Principal software partner & Project/product name \\
\hline Winner & Comet & Conchango & Project Odyssey \\
Runner Up & Deutsche Bank AG London & $\begin{array}{l}\text { Inxight (UK) } \\
\text { Commended }\end{array}$ & ntl:Group \\
Finalist & Barclaycard & SAS & Raptor (Real-Time Analytics Platform for Trading and Order Flow Representation) \\
Finalist & Barclaycard & AlM Technology & Network Visualisation \\
Finalist & Bombardier Transportation & Smart421 & Barclays Group Prospect File \\
Finalist & BT Exact & & Contact Centre Performance Measurement \\
Finalist & BT Exact & Deloitte & MicFAST Enterprise \\
Finalist & Halifax Bank of Scotland & Intelligent Travel/Task Estimation and Management System (ITEMS) \\
& (HBOS) Card Services & Hyperion Solutions & Decision Table evaluation and OPtimisation tol (DecTOP) \\
Finalist & ICAP & CDS (Corporate Document Services) & CSRS (Customer Service Reporting System) \\
Finalist & Interbrew UK & Unica Corporation/Kognitio & Minerva Customer Intelligence Platform \\
Finalist & Marks \& Spencer Money & ERIC 2003 \\
Finalist & NHS Estates (NHSE) & ASCKEY Data Services & Rogers Medical \\
Finalist & Rogers Medical Inc & Semagix Inc & Electronic Patient Records Programme \\
Finalist & South Tyneside & Cognos & IT Project portfolio management software implementation \\
& Healthcare Trust & Business Engine & Implementation of Applix TM1 \\
Finalist & Tesco Stores & Applix (UK) & The Vertex Way \\
Finalist & Thresher Group & & \\
Finalist & Vertex Customer Management & \\
\hline
\end{tabular}

Note: Finalists are listed in alphabetical order 
efficiency and profitability. For the first time, both stores and head office are using consistent data to measure results.

The information has also been structured to show associated buying patterns. For example, a high-achieving store might be making add-on sales of a particular software package every time it sells a computer. Managers at other stores can identify what lies behind this good performance and work to emulate the pattern through in-store marketing or better product placement. Head office too, is better equipped to respond to these selling patterns as, previously, the information held at head office did not always replicate that generated by the stores.

Having refined the MicroStrategy applications to meet Comet's needs, Conchango worked first with the IS team on preliminary user acceptance testing and then on a pilot involving 25 per cent of stores. The pilot was a great success and the new knowledge network was quickly extended to the remaining stores. Comet carried out its own training, which was minimal due to the intuitive 'click and use' front-end design implemented by Conchango. Users have only to sign onto the web-based portal and 'click' their way through the reports. To ensure that store managers' time was effectively utilised, the reports were laid out in such a way that the pertinent data was immediately available without having to 'drill or slice' the data. All reports were run overnight and cached for user access. This was a key component as the data warehouse could then be optimised to run 24 hours - head office users ad-hoc report against it during the day, without interference with their service levels from over 200 new users hitting the database as well. By caching the reports for each store, the data warehouse database did not have to be upgraded; network traffic was minimised; and the overall solution increased the optimisation of the existing infrastructure.

\section{EMPOWERING MANAGERS THROUGH SHARED KNOWLEDGE}

Conchango ensured that Comet's Project Odyssey delivered an information-based solution to give store managers the knowledge to increase the share of customer spend by selling more, higher-value products. Moreover, the company's senior management also have a tool enabling them to spot manager potential and to increase profitability with the help of accurate, daily sales information. Potential issues within stores, and trends by regions, can be easily spotted by head office users allowing corrective actions and new initiatives to be undertaken in less time.

By consolidating critical operational data in a consistent, easy-to-access format, Conchango has given Comet the opportunity to streamline its business processes by removing duplication of effort and inconsistent messages about product and turnover.

For more information on the Information Management Awards, please contact Lisa Di Bernardo, Elan Conferences Ltd, tel: +44 (0)1707 373701; e-mail: lisad@elanconf.co.uk

For more information on Conchango, please telephone +44 (0)20 72614444 or e-mail talktous@conchango.com 